\section{RESEARCH ARTICLE 10.1029/2021JC017957}

Key Points:

- Annual peak in depth-average temperature occurred prior to shelf transit of Hurricane Sally providing favorable intensification conditions

- Depth-average temperature was set up by a distinct cascade of weather events including persistent downwelling conditions

- Coupling of climatological downwelling winds and warm ocean temperatures suggests an elevated risk of storm intensification over the shelf

\section{Correspondence to:}

B. Dzwonkowski,

briandz@disl.org

\section{Citation:}

Dzwonkowski, B., Fournier, S. Lockridge, G., Coogan, J., Liu, Z., \& Park, K. (2021). Cascading weather events amplify the coastal thermal conditions prior to the shelf transit of Hurricane Sally (2020). Journal of Geophysical Research: Oceans, 126, e2021JC017957. https://doi. org/10.1029/2021JC017957

Received 27 AUG 2021 Accepted 27 NOV 2021

Author Contributions: Conceptualization: B. Dzwonkowski Data curation: B. Dzwonkowski, G. Lockridge, J. Coogan, K. Park Formal analysis: B. Dzwonkowski, S. Fournier, J. Coogan

Investigation: B. Dzwonkowski, S.

Fournier, J. Coogan, Z. Liu

Visualization: B. Dzwonkowski, S.

Fournier, J. Coogan

Writing - original draft: $B$.

Dzwonkowski

Writing - review \& editing: S. Fournier, G. Lockridge, J. Coogan, Z. Liu, K. Park

(C) 2021. The Authors

This is an open access article under the terms of the Creative Commons Attribution License, which permits use, distribution and reproduction in any medium, provided the original work is properly cited.

\section{Cascading Weather Events Amplify the Coastal Thermal Conditions Prior to the Shelf Transit of Hurricane Sally (2020)}

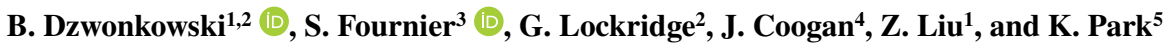 \\ ${ }^{1}$ University of South Alabama, Mobile, AL, USA, ${ }^{2}$ Dauphin Island Sea Lab, Dauphin Island, AL, USA, ${ }^{3}$ Jet Propulsion \\ Laboratory, California Institute of Technology, Pasadena, CA, USA, ${ }^{4}$ Woods Hole Oceanographic Institution, Woods Hole, \\ MA, USA, ${ }^{5}$ Texas A\&M University at Galveston, Galveston, TX, USA
}

\begin{abstract}
Changes in tropical cyclone intensity prior to landfall represent a significant risk to human life and coastal infrastructure. Such changes can be influenced by shelf water temperatures through their role in mediating heat exchange between the ocean and atmosphere. However, the evolution of shelf sea surface temperature during a storm is dependent on the initial thermal conditions of the water column, information that is often unavailable. Here, observational data from multiple monitoring stations and satellite sensors were used to identify the sequence of events that led to the development of storm-favorable thermal conditions in the Mississippi Bight prior to the transit of Hurricane Sally (2020), a storm that rapidly intensified over the shelf. The annual peak in depth-average temperature of $>29^{\circ} \mathrm{C}$ that occurred prior to the arrival of Hurricane Sally was the result of two distinct warming periods caused by a cascade of weather events. The event sequence transitioned the system from below average to above average thermal conditions over a 25-day period. The transition was initiated with the passage of Hurricane Marco (2020), which mixed the upper water column, transferring heat downward and minimizing the cold bottom water reserved over the shelf. The subsequent reheating of the upper ocean by surface heat flux from the atmosphere, followed by downwelling winds, effectively elevated shelf-wide thermal conditions for the subsequent storm, Hurricane Sally. The coupling of climatological downwelling winds and warm sea surface temperature suggest regions with such characteristics are at an elevated risk for storm intensification over the shelf.
\end{abstract}

Plain Language Summary Changes in tropical cyclone intensity prior to landfall represent a significant risk to human life and coastal infrastructure. Such changes can be influenced by sea surface temperatures as they provide the energy to tropical cyclones. However, the changes in sea surface temperatures during a storm depend on heat content in the coastal ocean before the storm arrives and the relevant information is often unavailable. Measurements from multiple monitoring stations and satellite sensors were used to identify the events that led to the development of favorable temperatures in the Mississippi Bight prior to the arrival of Hurricane Sally (2020), a storm that rapidly intensified. A sequence of two warming periods transitioned the coastal ocean from below average to above average temperatures over a 25-day period. The transition was initiated by Hurricane Marco (2020) which pumped heat from the ocean surface to deeper waters. This was followed by a reheating of the upper ocean and the offshore transport of warm coastal waters across the bottom of the shelf which packed the shelf with thermal energy that could feed the subsequent storm. The results suggest that coastlines with certain ocean and wind conditions may have an elevated risk of storm strengthening before landfall.

\section{Introduction}

Landfalling tropical cyclones are extreme events that represent a major threat to coastal regions across large swaths of the globe (Emanuel, 2005; Keim et al., 2007). An important factor limiting society's ability to mitigate loss of property and life from tropical cyclones centers around storm intensity, where forecasting progress has been slow relative to storm track (DeMaria et al., 2014; Kaplan \& DeMaria, 2003; Kaplan et al., 2010). Limitations in intensity forecasting are particularly important as storms approach shorelines where planning and response decisions have direct effects on the impacts of these events. Overcoming difficulties in intensity forecasting will have added importance in a warming future climate where storms are expected to be stronger and have increased precipitation rates (e.g., Bacmeister et al., 2018; Chu et al., 2020; Knutson et al., 2020; Liu et al., 2019; Vecchi et al., 2019). This appears to be particularly concerning in coastal regions as Chu et al. (2020) found there was a $150 \%$ increase in the expected number of category 3-5 storms making landfall under a carbon 
dioxide doubling scenario (but no additional increase for a quadrupling scenario). Furthermore, Emanuel (2017) highlighted that storms may intensify more rapidly before landfall under future warming climate scenarios, potentially making intensity prediction more challenging.

Landfall storm intensity is connected to coastal ocean conditions through sea surface temperature. The importance of this connection is highlighted by incorporation of sea surface temperature into the intensity potential parameter developed by Emanuel (1999) which indicates that the larger the difference between the sea surface and upper atmosphere temperatures, the stronger the potential wind speed. As a result, sea surface temperature modifications during a storm event have the potential to influence the evolution of a tropical cyclone. Such changes in sea surface temperature occur through a combination of vertical mixing, horizontal advection, upwelling and surface heat flux (Potter et al., 2017). While there can be significant storm to storm variability in the relative impacts of these four mechanisms (e.g., Potter et al., 2017), vertical mixing is generally found to be the dominant driver of upper ocean cooling (Price, 2009). Thus, this mixing potential implies that pre-storm thermal stratification (or lack thereof) has a significant impact on storm intensity at landfall. Shelves with high thermal stratification prior to storm passage have been linked to significant ahead-of-eye cooling and thus storm attenuation (Glenn et al., 2016; Park et al., 2019; Seroka et al., 2016). In contrast, homogeneous shelves have been shown to support sustained intensities or even intensification (Dzwonkowski et al., 2020; Miles et al., 2017; Potter et al., 2019; Pun et al., 2019; Zhang et al., 2019). Consequently, the initial shelf conditions over which air-sea interactions operate can significantly impact storm evolution prior to landfall.

The sequence of events that lead to particularly favorable or unfavorable shelf conditions can be challenging to assess because the importance of any particular storm event and its associated shelf crossing trajectory are extremely difficult to predict. As highlighted by Dzwonkowski et al. (2020), the sequence of events that set up the extreme shelf heat content prior to Hurricane Michael (2018) began nearly a month prior to the shelf intensification of this storm. Thus, planned data collections of such preconditioning are difficult, requiring most observational studies be based on platforms of opportunity. This issue is further exacerbated by the sparse availability of real-time subsurface information on shelf conditions, limiting the ability of forecasters to understand changes in sea surface temperature prior to landfall. Such temporal and spatial data limitations associated with tropical cyclones impacting shelves may be ameliorated, to varying extents, with the expansion of underwater glider programs. Nonetheless developing a better understanding of the impacts of shelf observations and the associated event sequences that drive conditions favorable to storm intensification is critical to forecasting landfall intensity of tropical cyclones. Furthermore, an enhanced understanding of event sequencing could also be used to better characterize the susceptibility of individual shelf regions to risks posed by tropical cyclones; for example, contributing event distributions could be used to develop co-occurrence probabilities.

The intense Atlantic storm activity of 2020, with eight landfall tropical cyclones in the Gulf of Mexico, provided multiple potential opportunities to improve the understanding of shelf setup processes. Of the storms entering the Gulf of Mexico, Hurricane Sally transited the Mississippi Bight and made landfall in Orange Beach, Alabama on the morning of September 16 (Berg \& Reinhart, 2021). While Hurricane Sally only achieved the status of a category 2 storm, the storm was only 1 knot below the wind speed required for classification as a major hurricane (Category 3-5). More importantly, it was a slow-moving storm (mean shelf transit speed of $\sim 8 \mathrm{~km} \mathrm{hr}^{-1}$ ) that rapidly intensified over the shelf ( 20 knots over $12 \mathrm{hr}$ ) leading to an extended period of high wind and waves in the region. The specific coastal ocean response to the passage of Hurricane Sally is the focus of another complimentary manuscript under preparation.

Here, we focus on the causal chain of events that led to an amplification of the heat content over the shelf in the Mississippi Bight prior to the arrival of Hurricane Sally. Similar to the work of Dzwonkowski et al. (2020) that focused on hurricane intensification from the summer 2018, the findings of this study highlight that events nearly a month prior to the arrival of Hurricane Sally were critical to setting up the shelf conditions. In the cases of Hurricane Michael (Dzwonkowski et al., 2020) and Hurricane Sally (this study), the passage of a tropical cyclone initiated the sequence of events that generated favorable shelf conditions for intensification of a subsequent storm. However, the initial storm response as well as the subsequent details in this case study deviate in notable ways and the findings suggest a coupling of climatological patterns that could be expected to produce hurricane "friendly" shelf regions. 


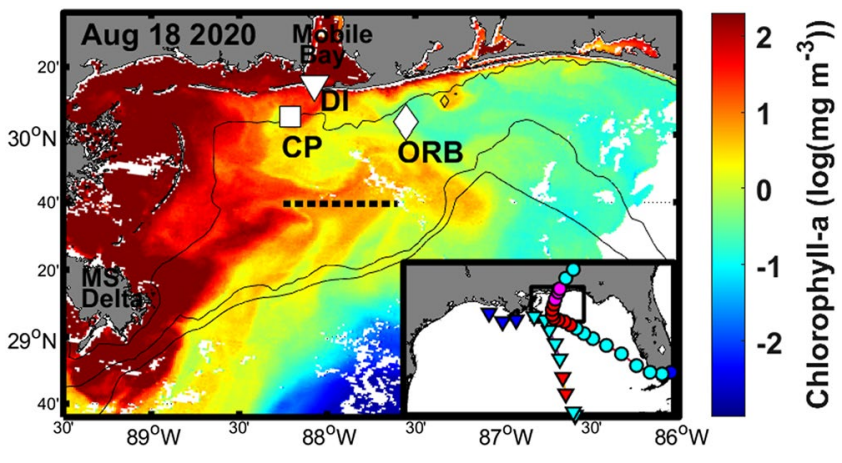

Figure 1. Map of the Mississippi Bight with high resolution (1 km) Terra MODIS ocean color data from 18 August 2020, highlighting the large plume of the Mississippi River water impacting the study region prior to the passage of Hurricane Marco on August 24. Locations of monitoring stations used in the Alabama coastal region are shown: site $\mathrm{CP}(\mathrm{CP}, \boldsymbol{\nabla})$, DPIA1 (DI, $\boldsymbol{\nabla})$ and the NOAA Orange Beach Buoy (ORB, $\bullet$ ) as well as the 20, 100, and $200 \mathrm{~m}$ isobaths (three solid lines). In addition, the estimated foot of a downwelling front using $28.5^{\circ} \mathrm{C}$ isotherm on September 14 is shown (dotted line). The inset shows the study region (black box) in the broader context of the Gulf of Mexico region with storm tracks for Hurricane Marco (August 21-25; triangles) and Hurricane Sally (September 12-16; circles). The coloration of symbols is associated with storm classifications: tropical depression (blue), tropical storm (cyan), hurricane-category 1 (red), and hurricane-category 2 (magenta).

\section{Data and Analysis}

The data sources, processing, and analysis follow similar methods as those in Dzwonkowski et al. $(2018,2020)$ with appropriately modified descriptions below.

\subsection{Tropical Cyclone Data}

Position data for Hurricanes Marco and Sally were acquired from the best track files for each storm as provided by National Oceanic and Atmospheric Administration (NOAA) National Hurricane Center (ftp://ftp.nhc.noaa.gov/ atcf/btk/).

\subsection{In Situ Data and Associated Analysis}

To understand the atmospheric and oceanic conditions on the shelf prior to the arrival of Hurricane Sally, field and reanalysis data from various sources were obtained. Standard meteorological data from two NOAA National Data Buoy Center (NDBC) stations were used (Figure 1): buoy station 42012 offshore of Orange Beach, AL (ORB, https://www.ndbc.noaa.gov/station_page. php?station=42012) and DPIA1 on Dauphin Island, AL (https://www.ndbc. noaa.gov/station_page.php?station=dpia1). The meteorological data included air temperature, relative humidity/dew point temperature, and wind speed and direction. These stations were the closest measurements available to the main mooring site (Compass Port, $\mathrm{CP}$ ) and have relatively long records (9 and 30 years at ORB and DPIA1, respectively). The sites are generally similar in magnitude and direction, however, there were significant differences during the period when Hurricane Sally was transiting the shelf. In addition, incoming solar radiation and relative humidity data from the Dauphin Island station of the Alabama Real-time Coastal Observing system were obtained for the study period (https:// arcos.disl.org/stations/disl_stations?stationnew=628). This site is less than $500 \mathrm{~m}$ away from DPIA1, and both sites are collectively referred to as site DI for this study (Figure 1). Additional key atmospheric variables, including solar radiation and long-wave radiation, were obtained from the National Centers for Environmental Prediction (NCEP) North American Region Reanalysis (NARR) for the grid cell closest to site ORB (https://www.esrl. noaa.gov/psd/data/gridded/data.narr.html). The NARR outputs are on $1 / 3^{\circ}$ grid $(\sim 32-\mathrm{km}$ resolution) and were interpolated from the 3 -hr outputs to hourly to match the DI and ORB data.

The hydrographic data were primarily derived from a long-term mooring station (site $\mathrm{CP}$ ) on the $20 \mathrm{~m}$ isobath to the west-southwest of Mobile Bay (Figure 1). The site provides a relatively long-term (15 years over the 2005-2020 period) perspective of shelf conditions from a suite of instruments. The instrument suite has changed over time, but typically consists of two CTD instruments to measure temperature and salinity at the bottom ( $\sim 0.4 \mathrm{~m}$ above bottom, mab or $\sim 19.6 \mathrm{~m}$ below the surface) and near-surface $(\sim 15.5 \mathrm{mab}$ or $\sim 4.5 \mathrm{~m}$ below the surface), and 4-9 thermistors throughout the water column to measure thermal structure. Details of the mooring configurations and aspects of the data processing can be found in various studies (e.g., Coogan et al., 2019; Dzwonkowski et al., 2020; Tzeng et al., 2016). Similar to the summer of 2018, the late summer of 2020 featured an additional data stream from a CTD on a surface buoy $(\sim 100 \mathrm{~m}$ apart from site CP), providing data at $\sim 19.6$ mab (i.e., $\sim 0.6 \mathrm{~m}$ below the surface). However, the extent of the data stream in 2020 was short-lived, reporting intermittently between July 31 and September 3. In order to fill the significant gaps in this surface measurement as well as provide a similar in situ sea surface temperature measured in previous years, sea surface temperature data from ORB ( 1-2 m below the surface) were combined with those from site CP for available data (10 years in 2009-2020, no available data in 2018). These data are available at the NOAA National Center for Environmental Information (NCEI: see the Acknowledgments for citation links).

The heat content/flux calculations were carried out following typical procedures. For heat content, the depth-average temperature was used given the shelf focus of the study (Potter et al., 2019; Price, 2009; Pun et al., 2019) and was calculated with water column temperature observations interpolated to a 1-m grid. While sea surface 
temperature is the means through which tropical cyclones interact with the ocean, this study focuses on depth-average temperature as averaging over the expected mixing depth of a storm has been suggested or shown be to the most relevant property for storm intensification (Balaguru et al., 2015, 2018), particularly over a shallow shelf (Potter et al., 2019; Price, 2009). The sensible and latent heat fluxes were calculated with the TOGA-COARE algorithms (Fairall et al., 1996) similar to other studies in the region (Coogan et al., 2019; Dzwonkowski et al., 2020). Incoming solar radiation data from site DI compared well to the NARR reanalysis data at $\mathrm{CP}$ and were used for the subsequent analysis. Upward solar radiation as well as long-wave radiation were taken from the NARR data. At a few time points, the sum of the downward solar radiation from DI and the upward solar radiation term from NARR resulted in small negative values, which were fixed to zero. Conversion between relative humidity and dew point temperature was conducted following standard algorithms (https://bmcnoldy.rsmas. miami.edu/Humidity.html) (Alduchov \& Eskidge, 1996; August, 1828; Magnus, 1844). Note that the dew point temperature data stream failed at ORB on September 15 prior to Hurricane Sally. As such, relative humidity at site DI was used in the heat flux calculations at site ORB thereafter. While no marine heatwaves were identified in this study period following the methods of Hobday et al. (2016), the 90th percentile was used as a reference point for extreme thermal conditions in the depth-average temperature time series.

Current velocity data throughout the water column were obtained from a Nortek Acoustic Doppler Waves and Current profiler (AWAC) at site CP. During the passage of Hurricane Sally, movement of the AWAC changed the pitch, roll, and heading of the instrument. Proprietary firmware from Nortek (Surge v1.15.03) was used to remap the bins to account for the change in orientation during this event period which resulted in the loss of some near-surface bins during Hurricane Sally (bin ranges changed from 1.5-17.0 mab to 1.0-14.5 mab on September 16). The resulting data were processed following the procedure in Dzwonkowski et al. (2014) where a 40-hr low-pass Lanczos filter was used to highlight low-frequency circulation patterns. These data are available at the Dauphin Island Sea Lab Data Management Center (https://www.disl.org/research/data-management-center) and NOAA NCEI (see the Acknowledgements for citation links).

The hydrographic and current velocity data at site $\mathrm{CP}$ were used to determine several water column stability parameters similar to those analyzed in Dzwonkowski et al. (2018). Direct measurements of the bulk shear squared (bulk $S^{2}$ ), bulk buoyancy frequency squared (bulk $N^{2}$ ), and bulk Richardson number (bulk $R i$ ) were determined:

$$
\begin{gathered}
\text { bulk } S^{2}=\left(\frac{\Delta u}{\Delta z}\right)^{2}+\left(\frac{\Delta v}{\Delta z}\right)^{2} \\
\text { bulk } N^{2}=\frac{-g}{\rho_{0}} \frac{\Delta \rho}{\Delta z} \\
\text { bulk } R i=\frac{\text { bulk } N^{2}}{\text { bulk } S^{2}}
\end{gathered}
$$

where $\Delta u$ and $\Delta v$ are along and across-shelf velocity differences between the upper and lower layers, respectively; $\Delta z$ is the distance between the layer velocities; $g$ is gravitational acceleration; $\Delta \rho$ is the density difference between the layers; and $\rho_{0}$ is the average density. Richardson number values less than or equal to the critical value $\left(R i_{c r}=0.25\right)$ are generally accepted to be indicative of mixing, although higher values $(0.25<R i<1)$ have been associated with mixing in some studies (e.g., Canuto et al., 2001). The bulk $S^{2}$ was calculated with an upper layer velocity at $17.0 \mathrm{mab}$ and a lower layer velocity at $3.0 \mathrm{mab}$ as these values provide a first order estimate of the shear. Similarly, density measurements at the near-surface and bottom CTD were used to determine bulk $N^{2}$.

\subsection{Satellite Data and Associated Analysis}

For determining the regional sea surface conditions, several satellite-based data sets were obtained. Sea surface temperature data were obtained from the Jet Propulsion Laboratory (JPL) Multi-scale Ultra-high Resolution (MUR) sea surface temperature product (https://podaac.jpl.nasa.gov/dataset/MUR-JPL-L4-GLOB-v4.1) which is available from 2003-present. This is a 1-km resolution product that blends $1-\mathrm{km}$ infrared sensor data and 25$\mathrm{km}$ microwave sensor data. A regional climatology for the northeastern Gulf of Mexico was developed using the available 17 years of data. The MUR sea surface temperature data were favored over the longer duration Optimal Interpolated sea surface temperature (OISST) product because of the shelf emphasis of the study region where higher spatial resolution was prioritized over the coarser resolution of the OISST product. In addition, 
Terra/MODIS L2 chlorophyll-a data (1 km resolution) from 18 August 2020 were used to provide a qualitative view of riverine/estuarine waters over the shelf prior to the arrival of Hurricane Marco. Such qualitative use of chlorophyll-a data from standard ocean color algorithms has been common in many previous studies (e.g., Dzwonkowski \& Yan, 2005; Walker et al., 2005).

\section{Results}

\subsection{Water Column Conditions}

The importance of event sequencing can be seen in the evolution of the depth-average temperature, a proxy for shelf heat content, which experienced a dramatic increase over the inner shelf during the month prior to Hurricane Sally increasing from $<27^{\circ} \mathrm{C}$ in mid-August to $>29.5^{\circ} \mathrm{C}$, the 2020 maximum, by September $10-11$ (Figure 2a). The peak was rapidly attenuated in response to the shelf crossing of Hurricane Sally (September 14-16), which initiated the fall transition to cooler, less stratified shelf conditions. Comparing the 2020 depth-average temperature evolution to the climatological conditions showed a transition from below average to above average conditions. While this increase in depth-average temperature did not reach the threshold for a "marine heatwave," the depth-average temperatures were well above values that have been statistically associated with rapidly intensifying tropical cyclones, for example, $<28.5^{\circ} \mathrm{C}$ per Kaplan and DeMaria (2003). Notably, this month-long period was marked by two episodes of warming (August 17-27 and September 5-11), both of which were associated with downwelling favorable wind conditions (Figure $2 \mathrm{~b}$ ). The first of these events was generated by the passage of Hurricane Marco to the south of the Mississippi Bight (Figure 1), while the second was associated with a more typical summer wind pattern that occurred prior to the arrival of Hurricane Sally on the shelf.

\subsection{Response to Hurricane Marco}

The first warming period (August 17-27), with an increase in depth-average temperature of $\sim 2.5^{\circ} \mathrm{C}$, was associated with the passage of tropical cyclone Marco and occurred as the shelf was transitioning from upwelling to downwelling conditions (Figures $2 \mathrm{a}$ and $2 \mathrm{~b}$ ). Despite the storm being well to the southwest of the Alabama shelf, the cyclonic winds associated with Marco produced strong downwelling conditions $\left(\sim 10 \mathrm{~m} \mathrm{~s}^{-1}\right.$ westward wind on August 23-26 in Figure 2b), which amplified the transition from upwelling to downwelling that began around August 18. During the initial transition, the water column velocity data showed generally weak currents in both the along and across-shelf directions (Figures $2 \mathrm{c}$ and $2 \mathrm{~d}$ ). Similarly, the thermal structure of the water column at site CP showed relaxing isotherms sloping downward with time (Figure 2e).

The impact of Hurricane Marco was clearly visible in both the velocity and temperature structure on August 2226. Unsurprisingly, the strong downwelling winds produced a very strong downwelling circulation with depth-average along-shelf currents around $60 \mathrm{~cm} \mathrm{~s}^{-1}$ and opposing across-shelf flows in the near-surface (onshore) and bottom (offshore) on the order of $30 \mathrm{~cm} \mathrm{~s}^{-1}$ (Figures $2 \mathrm{c}$ and $2 \mathrm{~d}$ ). This downwelling circulation generated a rapid thermal response on August 22-23 that began homogenizing the water column temperature to $\sim 29^{\circ} \mathrm{C}$, a value slightly lower than the pre-storm surface temperature (Figure 2e). Shortly thereafter (August 24), the surface cooled by $0.5-1{ }^{\circ} \mathrm{C}$ while the bottom continued to warm and then became completely mixed (August 26). Interestingly, these changes in the thermal structure resulted in no significant change in the depth-average temperature during this period (Figure 2a).

The salinity data at site CP brought additional context to the thermal response during the passage of Hurricane Marco (Figure 2f). The initial salinity response to the downwelling wind from Hurricane Marco showed a freshening of both the surface and bottom at site CP, dropping about 4 and 6 psu, respectively, on August 24-25. On August 26, 2 days after Marco passed just south of the Mississippi River Delta, the surface and bottom salinity began converging, an indication of mixing, and remained uniform for approximately a day. At the same time, the across-shelf current was dramatically reduced to $\sim 5 \mathrm{~cm} \mathrm{~s}^{-1}$ at both near-surface and near-bottom (Figure 2d).

Following the shelf response to the passage of Hurricane Marco, the system rapidly re-stratified with surface to bottom salinity differences of 4 psu and increasing to 8 psu by September 1 . This resulted in stronger salinity difference relative to the pre-Marco conditions (Figure 2f). In contrast, the thermal stratification was much slower to recover with surface to bottom temperature differences nearing the pre-Marco conditions around September 3-4, which lasted only for a short period of time till September 5 (Figure 2e). Importantly, the post-Marco thermal 


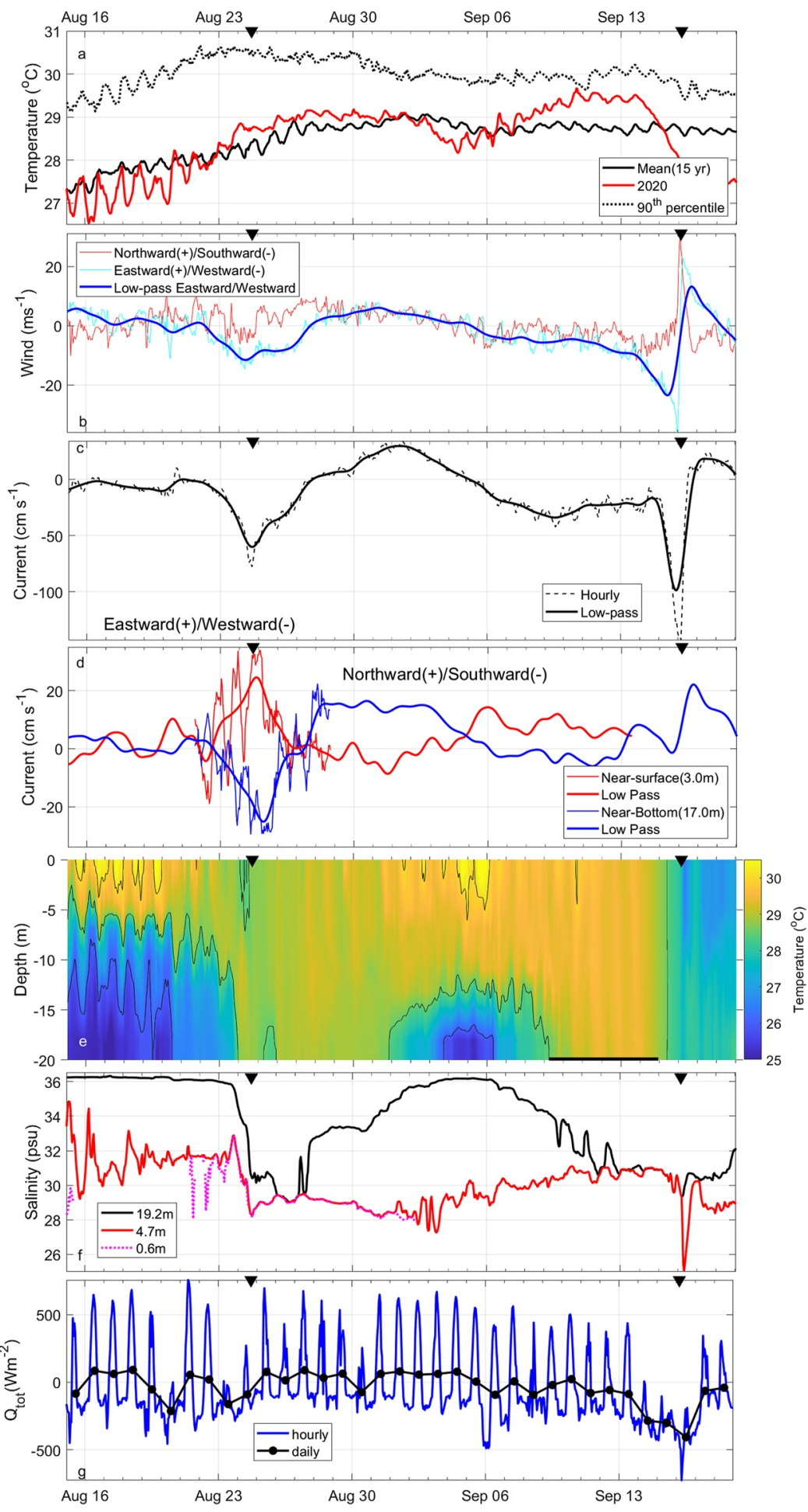

Figure 2. Evolution of the environmental data encompassing the period prior to, during and post landfall of Hurricane Sally including (a) depth-average temperature at site $\mathrm{CP}$ (red), a proxy for shelf heat content, (b) along and across-shelf wind speed components at $\mathrm{ORB}$, (c) along-shelf depth-average currents at site $\mathrm{CP}$, (d) near-surface and near-bottom across-shelf currents at site CP, (e) vertical temperature structure at site $\mathrm{CP}$, (f) salinity at site $\mathrm{CP}$, and (g) estimated surface heat flux at ORB. The inverse triangles at the top of each panel indicates the closest times to landfall for Hurricane Marco (24 August 2020) and landfall for Hurricane Sally (16 September 2020). The depths (m) in the legends are from the surface. Also shown in (a) are the long-term mean (black line) and the 90th percentile threshold (dotted line) based on the 15-year (2005-2020) data. In (e), the black contours indicate isotherms $\left(26^{\circ} \mathrm{C}, 28.5^{\circ} \mathrm{C}\right.$, and $\left.30^{\circ} \mathrm{C}\right)$ and the horizontal black line at the bottom indicates the downwelling period (September 9-14) over which a scaled advection of an observed front (using the $28.5^{\circ} \mathrm{C}$ isotherm) was applied to estimated offshore distance. 
structure was significantly different with a much thicker upper warm layer. This was particularly evident in the mid-water column structure where the $28.5^{\circ} \mathrm{C}\left(26^{\circ} \mathrm{C}\right)$ isotherm was at around $14 \mathrm{~m}(17 \mathrm{~m})$ below the surface on September 3 compared to around $7 \mathrm{~m}(13 \mathrm{~m})$ below the surface during the mid-August upwelling conditions (Figure 2e). Despite having nearly the same surface to bottom temperature difference there was a $\sim 1.3^{\circ} \mathrm{C}$ increase (from $\sim 27^{\circ} \mathrm{C}$ in mid-August to $\sim 28.3^{\circ} \mathrm{C}$ on September 5) in depth-average temperature, resulting in a much more favorable thermal environment for the subsequent tropical cyclone (i.e., Hurricane Sally).

\subsection{Pre-Hurricane Sally Response}

This favorable thermal environment was provided with an additional boost from the second warming period on September 5-11, with an increase in depth-average temperature of $\sim 1.3^{\circ} \mathrm{C}$, which was also associated with downwelling favorable wind conditions (Figures $2 \mathrm{a}$ and $2 \mathrm{~b}$ ). The system response to the downwelling wind forcing was consistent with expectations, that is, westward along-shelf flow and opposing across-shelf flow in the surface and bottom (Figures $2 \mathrm{c}$ and $2 \mathrm{~d}$ ). Water temperatures below $26^{\circ} \mathrm{C}$ at the bottom of site $\mathrm{CP}$ on September 3-5 were replaced by much warmer water (Figure $2 \mathrm{e}$ ) and the prolonged period of downwelling wind conditions eventually homogenized the water column by September 10. This was well before Hurricane Sally began to exert a significant influence over the shelf region. At this point (September 11), the warming trend in the depth-average temperature was arrested and remained around $29.4^{\circ} \mathrm{C}$ until the inner core of Hurricane Sally began approaching the shelf break on September 14 (Figure 2a).

\section{Discussion}

As noted, there were two critical periods of increasing shelf heat content associated with downwelling events. In addition to the individual behaviors of these events, the time interval between them (August 28-September 4) was also critical to the final pre-Sally shelf conditions. The key aspects of the processes driving the evolution of the thermal environment in the event sequence are discussed below.

\subsection{Downward Transfer of Heat From Mixing During Hurricane Marco}

Given that site $\mathrm{CP}$ was over a $100 \mathrm{~km}$ north of the center of Hurricane Marco, the relative importance of this event to the shelf heat budget is difficult to assess with the available observations. As can be seen from the time series of the current velocity and temperature structure (Figures $2 c-2 e$ ), the cold water that was advected offshore in the bottom boundary layer during Marco eventually returned by early September during the subsequent upwelling event. This suggests the advective impact of Marco on the shelf heat content was short lived. However, there was a much thicker upper warm layer relative to the prior upwelling period (September 4 vs. August 15), that suggests heat was transferred deeper into the water column, effectively storing thermal energy at depth for Hurricane Sally, due to mixing during Hurricane Marco.

To determine whether significant mixing was likely during the passage of Hurricane Marco, water column stability characteristics at site CP were examined as Hurricane Marco moved through the region (Figure 3). Beginning on August 23, the bulk $S^{2}$ and bulk $N^{2}$ started to exhibit opposing trends with shear increasing and stratification decreasing with $S^{2}$ having notable diurnal peaks. Diurnal cycles in $S^{2}$ have been previously identified at this site and have been linked with near-inertial oscillations that modulate the low frequency structure of the horizontal velocities (Dzwonkowski et al., 2018). This interaction of the high and low frequencies generated periods of high and low shear (e.g., thin red and blue lines in Figure 2d). At the same time, the low frequency downwelling flow was advecting the downwelling front offshore reducing the bulk $N^{2}$ (Figure 3a). The resulting bulk Ri maintained values below 1 from August 24-26 with several periods nearing the critical value of 0.25 (Figure 3b). During this period of low bulk $R i$, stratification was present but declined till August 26 when $\mathrm{N}^{2}$ became zero, indicating the strong shear observed was generating mixing in the water column. This becomes more apparent on August 25 when the surface and bottom salinities converge to 29 psu.

Interestingly, the initial site response was quite different from what might be expected from a water column solely experiencing mixing (i.e., converging of surface and bottom mass properties) as both the surface and bottom salinities dropped synchronously (August 23, Figure 2f). This highlights the role of downwelling advection in the system response to Hurricane Marco. In this case, satellite-derived ocean color imagery showed an extensive 

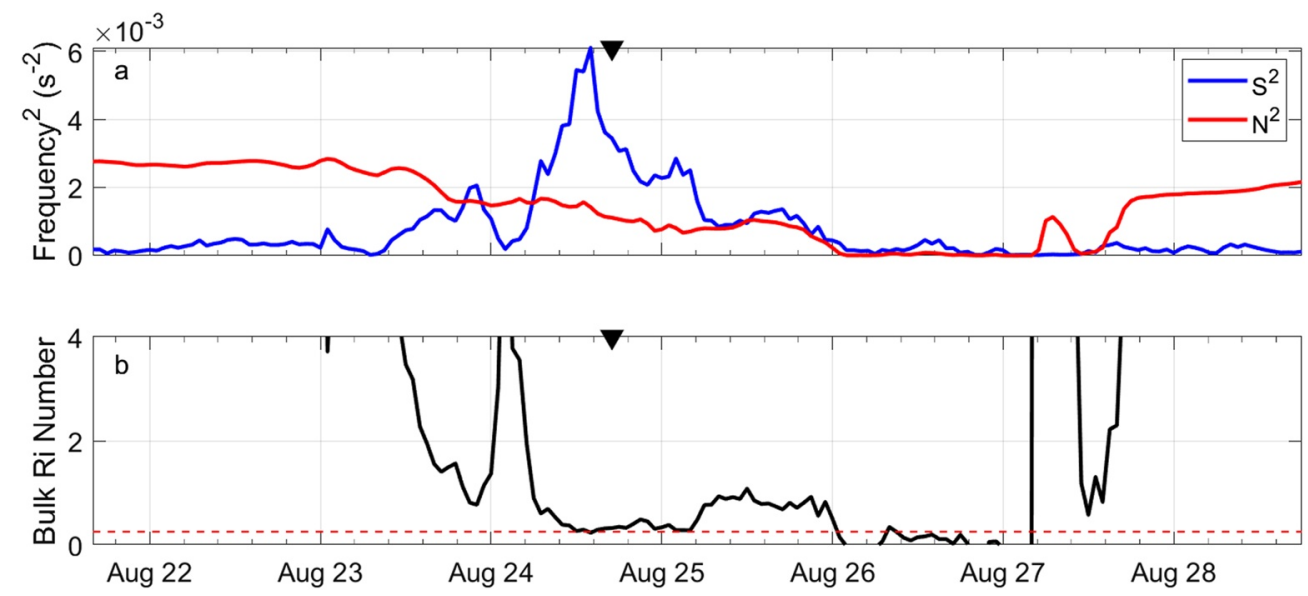

Figure 3. Time series of (a) the bulk buoyancy frequency (bulk $N^{2}$ ) and bulk horizontal vertical shear squared (bulk $S^{2}$ ) and (b) the bulk Richardson number (bulk $R i$ ) at site $\mathrm{CP}$ prior to, during and after the passage of Hurricane Marco. Also shown are the critical $R i\left(R i_{c r}=0.25\right)$, the horizontal red dashed line in (b), and the date of Marco passing just to the south of the Mississippi River Delta ( $)$.

river plume surging across much of the Mississippi Bight on August 18 (Figure 1). Thus, the onshore surface advection of this offshore buoyancy source coupled with the offshore transport of coastal water in the bottom boundary layer likely generated the synchronous drop in salinity, all of which was occurring in a highly sheared (relative to stratification) water column. This velocity shear would have been expected to erode the stratification through mixing.

Consequently, these data indicate that Hurricane Marco did induce mixing that transferred heat downward into the water column over the shelf. This is consistent with findings of Dzwonkowski et al. (2020) that showed a similar downward transfer of heat when Tropical Storm Gordon passed through the Mississippi Bight region approximately a month prior to Hurricane Michael, another storm that intensified while crossing the shelf. In the case of Hurricane Marco, the return of cool bottom temperatures to site CP indicated that the shelf was not "cleared" of its cold water reserve $\left(<26^{\circ} \mathrm{C}\right.$ on September 3-5 in Figure 2e). This may, in part, have been due to the presence of the extensive surface river plume emanating from the Mississippi River Delta, which would limit the mixing depth generated from the winds of Hurricane Marco. While buoyancy supplied by river plumes support hurricane strengthening in the open ocean (Balaguru et al., 2020; Domingues et al., 2021; Reul et al., 2021), the river discharge in this case may have indirectly inhibited the strengthening of a subsequent storm (Hurricane Sally) by limiting the amount of heat that was mixed to depth over the shelf by Hurricane Marco.

\subsection{Post-Hurricane Marco Thermal Recovery}

The next component of this event sequence was a re-warming of the upper ocean after Hurricane Marco as a result of favorable atmospheric conditions. Between August 25 and September 4, the region experienced positive net daily surface heat flux with the exception of August 30 (Figure 2g) which allowed the depth-average temperature to increase slightly immediately after the storm and maintained a temperature around $29^{\circ} \mathrm{C}$ for approximately a week between August 27 and September 2 (Figure 2a). The rewarming largely resulted from a reduction of the outgoing latent and sensible heat flux terms (relative to the incoming solar radiation) associated with reduced air-sea temperature differences and wind conditions during this period.

While the full water column initially warmed in response to the surface heat flux, over time the thermal structure showed a clear divergence with the upper water column re-warming and the lower water column cooling. Thus, the post-Marco positive net surface heat flux sustained the depth-average temperature over the inner shelf despite upwelling conditions advecting cooler bottom water that was displaced offshore during the previous downwelling condition (i.e., winds associated with Hurricane Marco). Importantly, the warm surface layer extended to a much greater depth relative to the pre-Marco conditions. This response is also largely consistent with the findings of Dzwonkowski et al. (2020) that noted the breakdown of stratification was critical in the rapid rewarming of the upper water column and was a key component of the compounding processes that drove a coastal marine 
heatwave in 2018 before landfall of Hurricane Michael. It should be noted that eventually the cooler bottom water associated with the upwelling did reduce the shelf heat content, dropping the depth-average temperature by approximately $0.5^{\circ} \mathrm{C}$ on September 4-5 (Figure 2a). Nonetheless, the depth-average temperature at site CP was still notably higher than the pre-Marco conditions and both contributing factors (i.e., vertical mixing and rewarming) would be expected to have occurred over the broader shelf region significantly increasing the heat content across the Mississippi Bight region.

\subsection{Impact of the Pre-Sally Downwelling}

This increase in depth-average temperature across the shelf was amplified by a final downwelling event leading up to the arrival of Hurricane Sally. This persistent downwelling event effectively cleared the inner shelf of any cool water (Figure 2e) and would be expected to continue advecting the pool of cooler bottom shelf water well beyond the mooring location. Such cold pool behavior was captured in the mid-Atlantic Bight with coupled glider observations and numerical modeling outputs during Hurricane Sandy in 2012 (Miles et al., 2017). The cold pool advection was shown to be consistent with the scaling arguments of Austin and Lentz (2002), where frontal distance offshore $\left(x_{e k}\right)$ could be represented as:

$$
x_{e k}(t)=X_{o}+\sqrt{\int_{0}^{t} \frac{2 * U_{s}}{\alpha} d t}
$$

for events beyond an inertial period where $t$ is time, $X_{o}$ is the initial position of the front, $\alpha$ is shelf slope, and $U_{s}$ is Ekman surface transport $=\tau_{s} /\left(\rho_{o} f\right)$ where $\tau_{s}$ is along-shelf wind stress, $\rho_{o}$ is a reference density, and $f$ is the Coriolis parameter. Applying this scaling to the period of time prior to the arrival of Hurricane Sally when the $28.5^{\circ} \mathrm{C}$ contour, a water temperature associated with rapid intensification, was observed to be passing by site $\mathrm{CP}$ ( $\sim$ September 9 ) suggests that this isotherm would be $\sim 48 \mathrm{~km}$ south of the CP/ORB mooring locations $(64 \mathrm{~km}$ offshore), putting the foot of the $28.5^{\circ} \mathrm{C}$ contour around the $40 \mathrm{~m}$ isobath, more than half the distance to the shelf break by September 14. This is consistent with the sea surface temperature data on September 14 (not shown), which showed the broader shelf area being above $28.5^{\circ} \mathrm{C}$. Thus, this sequence of events leading up to the arrival of Hurricane Sally, that is, the erosion of cooler bottom water from Hurricane Marco coupled with the subsequent offshore advection of the remaining bottom water, likely created a very large region of the shelf packed with very warm water. Similarly, pre-storm thermal conditioning on the Texas shelf was associated with the intensification of Hurricane Harvey in 2017 (Potter et al., 2019).

It is important to recognize some of the limitations associated with this component of the study. The interaction between the coastal ocean and an approaching tropical cyclone occurs over a larger area than what can be realistically captured by a singular point source. The inherent complexity of the Mississippi Bight with multiple sources of river discharge, including the Mississippi River discharge, as well as Loop Current eddies impinging on the outer shelf, create a situation that requires additional spatial information to gain a fuller understanding of the airsea interactions that set up the broader shelf conditions prior to the arrival of Hurricane Sally. Nonetheless, the mooring data used in this study still provide new perspectives on the event sequences that significantly impact the pre-conditioning of continental shelves.

\subsection{Climatology Coupling of Temperature and Wind}

Given that both warm upper ocean temperatures and downwelling favorable winds were primary drivers in amplifying the coastal ocean heat content, the likelihood of their co-occurrence during this period of peak hurricane activity represents a potentially important climatological coupling. Long-term observations of wind stress from both ORB (9-year) and DI (30 years) indicated downwelling winds dominated from mid-August to mid-September in this region (Figure 4). While there was significant interannual variability in the strength of the wind stress, the mean of every year during this active storm period (August 15-September 14) was downwelling favorable. The relatively shorter time series at site ORB suggested that the 2020 study period was associated with anomalously strong downwelling winds during this time period; however the longer perspective of site DI showed that there were other years similar in strength or stronger. 


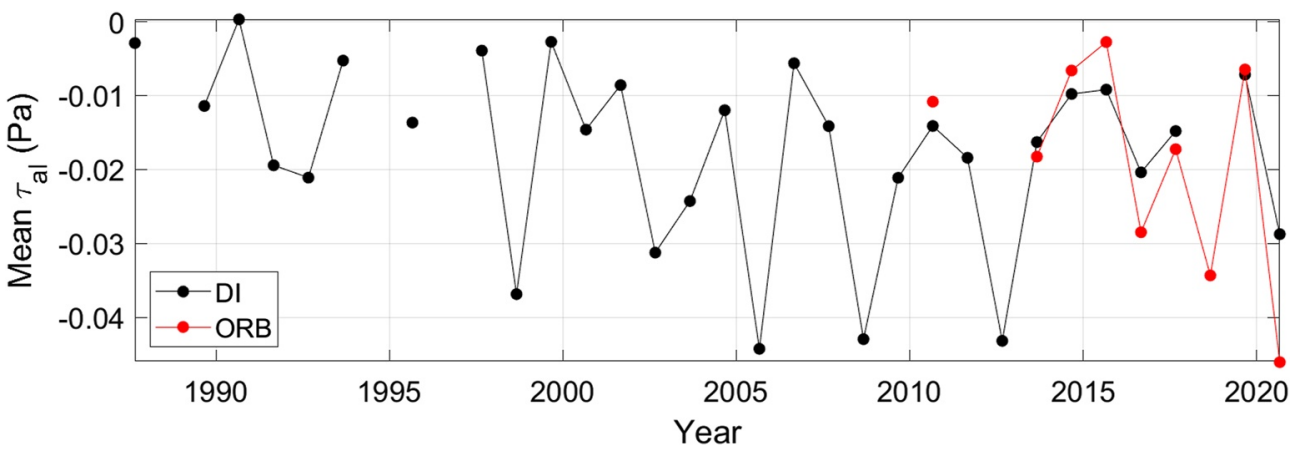

Figure 4. Mean along-shelf wind stress during the period between August 15 and September 15 from long-term records at ORB (red) and DI (black), 9 and 30 years, respectively. The negative wind stress indicates westward wind that favor downwelling. Gaps in the time series occur in years where data was not available for the time period.

Similarly, MUR sea surface temperature data over the shelf indicated the 2020 study period prior to Sally was generally above average but not extreme (not shown). In general, the climatological MUR sea surface temperature conditions from mid-August to mid-September showed the fall transition to cooler temperatures, with the transition beginning at shallow coastal waters first (Figure 5). Thus, the typical wind conditions during this time period coupled with the climatological sea surface temperature gradient would be expected to regularly feature downwelling events that deliver warmer offshore surface water to the coast and advect any reserve of colder bottom water offshore. This coupling of seasonal characteristics provides a coastal setting that is climatologically set-up to produce favorable conditions for tropical cyclone intensification as they transit the shelf. Thus, understanding the potential coupling of the drivers associated with the event sequence identified in this study is an important step for improving probabilistic representations of potential risk associated with hazards from tropical cyclones.

To expand the analysis beyond the Alabama coast, wind data from the NARR reanalysis was used to solve the $\mathrm{U}_{\mathrm{s}} / \alpha$ term from Equation 4 throughout the Gulf of Mexico and south Atlantic coast (Figure 6). This term can be used to highlight regions that experience periods of significant downwelling during the peak of the Atlantic hurricane season and can potentially lead to increased heat content over the shelf for storm intensification. The average winds from August 1 to October 31 across 41 years (1979-2020) of data were used, and slopes were calculated from the shoreline to the $100 \mathrm{~m}$ isobath. The distribution of this parameter showed the northern Gulf of Mexico was largely downwelling favorable during this time period with the Louisiana coast (i.e., coastline of the central northern Gulf of Mexico) being a hot spot for potential intensification due to the wide shelf and average westward winds. Such potential for favorable shelf thermal conditions in the northern Gulf of Mexico during the peak of hurricane season may contribute to the observed and simulated tendency of tropical cyclones to rapidly intensify before landfall in this region (Emanuel, 2017; Landsea \& Franklin, 2013).

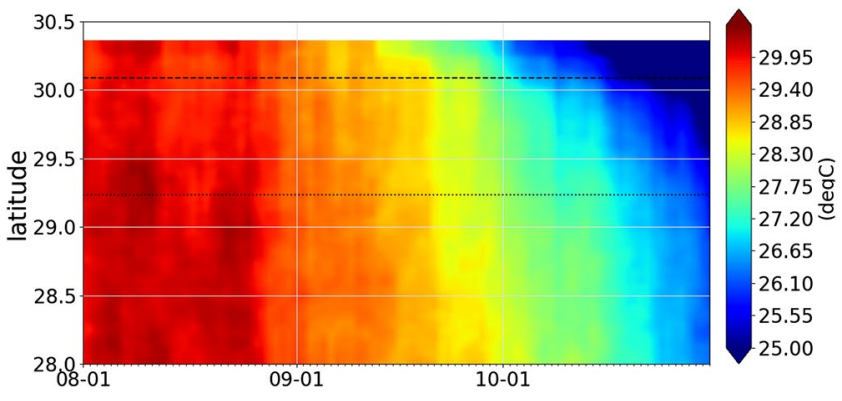

Figure 5. Hovmoller diagram of the climatological Multi-scale Ultra-high Resolution sea surface temperature pattern during August-October, derived from the 2003-2020 data, across the Mississippi Bight shelf and offshore along the longitude of site $\mathrm{CP}$. The dashed and dotted lines indicate the locations of site $\mathrm{CP}$ and the shelf break.
While the prospective of this study focuses on the potential importance of the resulting elevated heat content in the coastal ocean for the intensification of Hurricane Sally, the depth-average temperature in and of itself can be viewed as a coastal hazard. There is a rapidly growing body of work that highlights the impacts of marine heatwaves on ecosystems (e.g., Frölicher \& Laufkötter, 2018; Garrabou et al., 2009; Wernberg et al., 2013). As such, the event sequence that elevates the depth-average temperature and the potential climatological coupling of its drivers should be considered in the management of thermally sensitive ecosystems (e.g., coral reefs).

\section{Conclusion}

While continental shelves are relatively small regions of the global ocean, these regions are a critical transition zone that tropical cyclones must cross prior to landfall. Despite short periods of time spent over these regions (relative to the life span of a tropical cyclone), important modifications of storm characteristics can occur from the air-sea interactions. Importantly, 


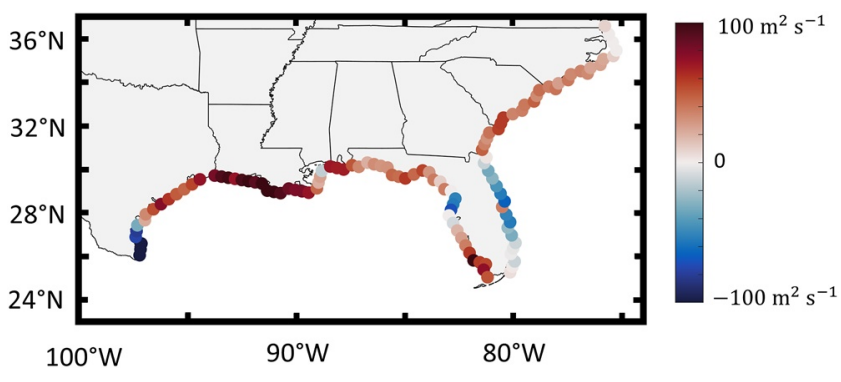

Figure 6. Relative comparison of the $\frac{U_{s}}{\alpha}$ term in the scaling argument (Equation 4) based on average winds from August 1 to October 31 (19792020) using wind data from the North American Region Reanalysis where red denotes downwelling winds and blue denotes upwelling winds. The darker the shading the more predominant the advective response is expected to be in that region.

understanding the initial coastal ocean conditions may become increasingly critical as some recent work indicates a slowing of mid-latitude tropical cyclones under warming climate scenarios (Yamaguchi \& Maeda, 2020). While much uncertainty surrounds such future behavior, a slowing of storms would provide more time over continental shelf environments allowing for more airsea interactions prior to landfall. Thus, the potential slower speed of storms as well as the observed slower decay rate over land (Li \& Chakraborty, 2020), both emphasize the importance of understanding the processes that set up the initial thermal conditions in the coastal ocean, a primary source of storm energy before landfall.

In the case of Hurricane Sally, observational data from regional monitoring systems provided context for the state of the initial thermal conditions as well as the event sequence that drove the evolution of the observed hydrographic conditions. This study found that the depth-average temperature prior to Hurricane Sally reached $29.4^{\circ} \mathrm{C}$, the 2020 annual peak and was approximately $0.7^{\circ} \mathrm{C}$ above the 15 -year mean for the study time period. This peak in heat content was driven by a sequence of events that included the passage of Hurricane Marco and a persistent weather pattern that generated strong downwelling conditions. Interestingly, this work suggests that an indirect impact of freshwater over the shelf (i.e., limiting the downward transfer of heat during Marco and subsurface storage) may have limited the thermal energy available to Sally. However, the subsequent advection of a downwelling front approximately $64 \mathrm{~km}$ offshore likely exposed more than $50 \%$ of shelf region to nearly homogeneous water column conditions with temperatures exceeding $28.5^{\circ} \mathrm{C}$. Thus, the event sequence shaping the thermal conditions over the shelf effectively produced a runway for intensification as Hurricane Sally crossed the shelf.

Given the identified event sequence and the climatological patterns of wind stress and warm upper ocean temperature during the study time period, hurricanes passing through this region of the Gulf of Mexico are likely to encounter favorable shelf conditions for intensification. The identification of other regions with such characteristics during hurricane season may provide additional context for anticipating the intensity response prior to landfall.

\section{Acknowledgments}

This work would not have been possible without the many folks that have passed through the Tech Support Group at the Dauphin Island Sea Lab to help maintain site CP over the years. We thank Rich Pawlowicz at the University of British Columbia for the freely available MATLAB m_map toolbox and Chris Landsea of NOAA NHC for providing links to early versions of the NOAA NHC best track data for 2020 storms. This paper is a result of research funded by the National Oceanic and Atmospheric Administration's RESTORE Science Program under awards NA17NOS4510101 and NA19NOS4510194 to the University of South Alabama and Dauphin Island Sea Lab and by the NASA Physical Oceanography program under award 80NSSC21K0553 and WBS 281945.02.25.04.67 to the University of South Alabama and the Jet Propulsion Laboratory. A portion of this work was conducted at the Jet Propulsion Laboratory, California Institute of Technology, under contract with NASA. We thank the NASA Goddard Space Flight Center, Ocean Ecology Laboratory, Ocean Biology Processing Group for the Moderate-resolution Imaging Spectroradiometer (MODIS) Terra ocean color data; 2014 Reprocessing. NASA OB.DAAC, Greenbelt, MD, USA. 10.5067/AQUA/ MODIS/MODIS_OC.2014.0.

\section{Data Availability Statement}

All data that were not downloaded from public sources have been made publicly available through the Dauphin Island Data Management Center (https://www.disl.edu/research/data-management-center) and (or have been submitted to) the NOAA National Center for Environmental Information (NCEI). In particular, site $\mathrm{CP}$ data are available at the following links: https://accession.nodc.noaa.gov/0211052; https://www.ncei. noaa.gov/access/metadata/landing-page/bin/iso?id=gov.noaa.nodc:0241013; $\quad$ https://data.nodc.noaa.gov/ cgi-bin/iso?id=gov.noaa.nodc:0203749; https://www.ncei.noaa.gov/archive/accession/0243995; https://doi. org/10.25921/q1tz-3b62; https://doi.org/10.25921/yy2w-ad34; https://doi.org/10.25921/gnd8-5h49; and https:// doi.org/10.25921/5za5-aw02.

\section{References}

Alduchov, O. A., \& Eskidge, R. E. (1996). Improved Magnus form approximation of saturation vapor pressure. Journal of Applied Meteorology and Climatology, 35(4), 601-609. https://doi.org/10.1175/1520-0450(1996)035<0601:imfaos>2.0.co;2

August, E. F. (1828). Ueber die Berechnung der Expansivkraft des Wasserdunstes. Annals of Physics, 89(5), 122-137. https://doi.org/10.1002/ andp. 18280890511

Austin, J., \& Lentz, S. (2002). The inner shelf response to wind-driven upwelling and downwelling. Journal of Physical Oceanography, 32, 2171-2193. https://doi.org/10.1175/1520-0485(2002)032<2171:tisrtw>2.0.co;2

Bacmeister, J. T., Reed, K. A., Hannay, C., Lawrence, P., Bates, S., Truesdale, J. E., et al. (2018). Projected changes in tropical cyclone activity under future warming scenarios using a high-resolution climate model. Climatic Change, 146, 547-560. https://doi.org/10.1007/ s10584-016-1750-x

Balaguru, K., Foltz, G. R., Leung, L. R., D'Asaro, E., Emanuel, K. A., Liu, H., \& Zedler, S. E. (2015). Dynamic Potential Intensity: An improved representation of the ocean's impact on tropical cyclones. Geophysical Research Letters, 42(16), 6739-6746. https://doi. org/10.1002/2015gl064822

Balaguru, K., Foltz, G. R., Leung, L. R., Hagos, S. M., \& Judi, D. R. (2018). On the use of ocean dynamic temperature for hurricane intensity forecasting. Weather and Forecasting, 33(2), 411-418. https://doi.org/10.1175/waf-d-17-0143.1

Balaguru, K., Foltz, G. R., Leung, L. R., Kaplan, J., Xu, W., Reul, N., \& Chapron, B. (2020). Pronounced impact of salinity on rapidly intensifying tropical cyclones. Bulletin of the American Meteorological Society, 101(9), E1497-E1511. https://doi.org/10.1175/bams-d-19-0303.1 
Berg, R., \& Reinhart, B. J. (2021). Hurricane Sally (AL192020): 11-17 September 2021. National Hurricane Center Tropical Cyclone Report. NOAA/National Weather Service/National Hurricane Center. https://www.nhc.noaa.gov/data/tcr/AL192020_Sally.pdf

Canuto, V. M., Howard, A., Cheng, Y., \& Dubovikov, M. S. (2001). Ocean turbulence. Part I: One-point closure model-momentum and heat vertical diffusivities. Journal of Physical Oceanography, 31, 1413-1426. https://doi.org/10.1175/1520-0485(2001)031<1413:otpiop>2.0.co;2

Chu, J. E., Lee, S. S., Timmermann, A., Wengel, C., Stuecker, M. F., \& Yamaguchi, R. (2020). Reduced tropical cyclone densities and ocean effects due to anthropogenic greenhouse warming. Science Advances, 6(51), eabd5109. https://doi.org/10.1126/sciadv.abd5109

Coogan, J., Dzwonkowski, B., \& Lehrter, J. (2019). Effects of coastal upwelling and downwelling on hydrographic variability and dissolved oxygen in Mobile Bay. Journal of Geophysical Research: Oceans, 124(2), 791-806. https://doi.org/10.1029/2018jc014592

DeMaria, M., Sampson, C. R., Knaff, J. A., \& Musgrave, K. D. (2014). Is tropical cyclone intensity guidance improving? Bulletin of the American Meteorological Society, 95(3), 387-398. https://doi.org/10.1175/bams-d-12-00240.1

Domingues, R., Le Hénaff, M., Halliwell, G., Zhang, J. A., Bringas, F., Chardon, P., et al. (2021). Ocean conditions and the intensification of three major Atlantic hurricanes in 2017. Monthly Weather Review, 149(5), 1265-1286. https://doi.org/10.1175/mwr-d-20-0100.1

Dzwonkowski, B., Coogan, J., Fournier, S., Lockridge, G., Park, K., \& Lee, T. (2020). Compounding impact of severe weather events fuels marine heatwave in the coastal ocean. Nature Communications, 11, 4623. https://doi.org/10.1038/s41467-020-18339-2

Dzwonkowski, B., Fournier, S., Park, K., Dykstra, S. L., \& Reager, J. T. (2018). Water column stability and the role of velocity shear on a seasonally stratified shelf, Mississippi Bight, northern Gulf of Mexico. Journal of Geophysical Research: Oceans, 123(8), 5777-5796. https:// doi.org/10.1029/2017jc013624

Dzwonkowski, B., Park, K., Lee, J., Webb, B. M., \& Valle-Levinson, A. (2014). Spatial variability of flow over a river-influenced inner shelf in coastal Alabama during spring. Continental Shelf Research, 74, 25-34. https://doi.org/10.1016/j.csr.2013.12.005

Dzwonkowski, B., \& Yan, X.-H. (2005). Development and application of a neural network based ocean colour algorithm in coastal waters. International Journal of Remote Sensing, 26(6), 1175-1200. https://doi.org/10.1080/01431160512331326549

Emanuel, K. (1999). Thermodynamic control of hurricane intensity. Nature, 401(6754), 665-669. https://doi.org/10.1038/44326

Emanuel, K. (2005). Increasing destructiveness of tropical cyclones over the past 30 years. Nature, 436, 686-688. https://doi.org/10.1038/ nature 03906

Emanuel, K. (2017). Will global warming make hurricane forecasting more difficult? Bulletin of the American Meteorological Society, 98(3), 495-501. https://doi.org/10.1175/bams-d-16-0134.1

Fairall, C., Bradley, E., Rogers, D., Edson, J., \& Young, G. (1996). Bulk parameterization of air-sea fluxes for Tropical Global Atmosphere Coupled-Ocean Atmosphere Response Experiment. Journal of Geophysical Research, 101, 3747-3764. https://doi.org/10.1029/95jc03205

Frölicher, T. L., \& Laufkötter, C. (2018). Emerging risks from marine heat waves. Nature Communications, 9, 650. https://doi.org/10.1038/ s41467-018-03163-6

Garrabou, J., Coma, R., Bensoussan, N., Bally, M., Chevaldonne, P., Cigliano, M., et al. (2009). Mass mortality in Northwestern Mediterranean rocky benthic communities: Effects of the 2003 heat wave. Global Change Biology, 15, 1090-1103. https://doi.org/10.1111/j.1365-2486.2008.01823.x

Glenn, S. M., Miles, T. N., Seroka, G. N., Xu, Y., Forney, R. K., Yu, F., et al. (2016). Stratified coastal ocean interactions with tropical cyclones. Nature Communications, 7, 10887. https://doi.org/10.1038/ncomms10887

Hobday, A. J., Alexander, L. V., Perkins, S. E., Smale, D., Straub, S., Olive, E. C. J., et al. (2016). A hierarchical approach to defining marine heatwaves. Progress in Oceanography, 141, 227-238. https://doi.org/10.1016/j.pocean.2015.12.014

Kaplan, J., \& DeMaria, M. (2003). Large-scale characteristics of rapidly intensifying tropical cyclones in the North Atlantic basin. Weather and Forecasting, 18(6), 1093-1108. https://doi.org/10.1175/1520-0434(2003)018<1093:lcorit>2.0.co;2

Kaplan, J., DeMaria, M., \& Knaff, J. A. (2010). A revised tropical cyclone rapid intensification index for the Atlantic and eastern North Pacific basins. Weather and Forecasting, 25(1), 220-241. https://doi.org/10.1175/2009waf2222280.1

Keim, B. D., Muller, R. A., \& Stone, G. W. (2007). Spatiotemporal patterns and return periods of tropical storm and hurricane strikes from Texas to Maine. Journal of Climate, 20(14), 3498-3509. https://doi.org/10.1175/jcli4187.1

Knutson, T., Camargo, S. J., Chan, J. C. L., Emanuel, K., Ho, C.-H., Kossin, J., et al. (2020). Tropical cyclones and climate change assessment: Part II: Projected response to anthropogenic warming. Bulletin of the American Meteorological Society, 101(3), E303-E322. https://doi. org/10.1175/bams-d-18-0194.1

Landsea, C. W., \& Franklin, J. L. (2013). Atlantic hurricane database uncertainty and presentation of a new database format. Monthly Weather Review, 141, 3576-3592. https://doi.org/10.1175/MWR-D-12-00254.1

Li, L., \& Chakraborty, P. (2020). Slower decay of landfalling hurricanes in a warming world. Nature, 587, 230-234. https://doi.org/10.1038/ s41586-020-2867-7

Liu, M., Vecchi, G. A., Smith, J. A., \& Knutson, T. R. (2019). Causes of large projected increases in hurricane precipitation rates with global warming. npj Climate and Atmospheric Science, 2, 38. https://doi.org/10.1038/s41612-019-0095-3

Magnus, G. (1844). Versuche über die Spannkräfte des Wasserdampfs. Annals of Physics, 137(2), 225-247. https://doi.org/10.1002/ andp. 18441370202

Miles, T., Seroka, G., \& Glenn, S. (2017). Coastal ocean circulation during Hurricane Sandy. Journal of Geophysical Research: Oceans, 122(9), 7095-7114. https://doi.org/10.1002/2017jc013031

Park, J.-H., Yeo, D.-E., Lee, K., Lee, H., Lee, S. W., Noh, S., et al. (2019). Rapid decay of slowly moving Typhoon Soulik (2018) due to interactions with the strongly stratified northern East China Sea. Geophysical Research Letters, 46(24), 14595-14603. https://doi. org/10.1029/2019g1086274

Potter, H., DiMarco, S. F., \& Knapp, A. H. (2019). Tropical cyclone heat potential and the rapid intensification of Hurricane Harvey in the Texas Bight. Journal of Geophysical Research: Oceans, 124(4), 2440-2451. https://doi.org/10.1029/2018jc014776

Potter, H., Drennan, W. M., \& Graber, H. C. (2017). Upper ocean cooling and air-sea fluxes under typhoons: A case study. Journal of Geophysical Research: Oceans, 122(9), 7237-7252. https://doi.org/10.1002/2017jc012954

Price, J. F. (2009). Metrics of hurricane-ocean interaction: Vertically-integrated or vertically-averaged ocean temperature? Ocean Science, 5(3), 351-368. https://doi.org/10.5194/os-5-351-2009

Pun, I.-F., Chan, J. C. L., Lin, I.-I., Chan, K. T. F., Price, J. F., Ko, D. S., et al. (2019). Rapid intensification of Typhoon Hato (2017) over shallow water. Sustainability, 11(13), 3709. https://doi.org/10.3390/su11133709

Reul, N., Chapron, B., Grodsky, S. A., Guimbard, S., Kudryavtsev, V., Foltz, G. R., \& Balaguru, K. (2021). Satellite observations of the sea surface salinity response to tropical cyclones. Geophysical Research Letters, 48(1), e2020GL091478. https://doi.org/10.1029/2020GL091478

Seroka, G., Miles, T., Xu, Y., Kohut, J., Schofield, O., \& Glenn, S. (2016). Hurricane Irene sensitivity to stratified coastal ocean cooling. Monthly Weather Review, 144(9), 3507-3530. https://doi.org/10.1175/mwr-d-15-0452.1

Tzeng, M. W., Dzwonkowski, B., \& Park, K. (2016). Data processing for a small-scale long-term coastal ocean observing system near Mobile Bay, Alabama. Earth and Space Science, 3(12), 510-522. https://oi.org/10.1002/2016ea000188 
Vecchi, G. A., Delworth, T. L., Murakami, H., Underwood, S. D., Wittenberg, A. T., Zeng, F., et al. (2019). Tropical cyclone sensitivities to CO doubling: Roles of atmospheric resolution, synoptic variability and background climate changes. Climate Dynamics, 53(9-10), 5999-6033. https://doi.org/10.1007/s00382-019-04913-y

Walker, N. D., Leben, R. R., \& Balasubramanian, S. (2005). Hurricane-forced upwelling and chlorophyll a enhancement within cold-core cyclones in the Gulf of Mexico. Geophysical Research Letters, 32, L18610. https://doi.org/10.1029/2005GL023716

Wernberg, T., Smale, D. A., Tuya, F., Thomsen, M. S., Langlois, T. J., de Bettignies, T., et al. (2013). An extreme climatic event alters marine ecosystem structure in a global biodiversity hotspot. Nature Climate Change, 3, 78-82. https://doi.org/10.1038/nclimate1627

Yamaguchi, M., \& Maeda, S. (2020). Slowdown of Typhoon translation speeds in mid-latitudes in September influenced by the Pacific Decadal Oscillation and global warming. Journal of the Meteorological Society of Japan, 98(6), 1321-1334. https://doi.org/10.2151/jmsj.2020-068

Zhang, Z., Wang, Y., Zhang, W., \& Xu, J. (2019). Coastal ocean response and its feedback to Typhoon Hato (2017) over the South China Sea: A numerical study. Journal of Geophysical Research: Atmospheres, 124(24), 13731-13749. https://doi.org/10.1029/2019jd031377 